\title{
Study of Complex Recovery of Solid Slag Waste from Thermal Power Plants in the Target Components
}

\author{
A. A. Hlopitskiy \\ Department of Inorganic matters technology and ecology, Ukrainian State University of Chemical Technology, Ukraine
}

Copyright (c) 2015 Horizon Research Publishing All rights reserved.

\begin{abstract}
The paper presents a study aimed at a comprehensive treatment of solid slag waste from thermal power plants. By waste magnetic separation, it is possible to extract valuable components for further use. Reagents were selected and parameters to obtain "sesqui" oxide and calcium oxide were laid down.
\end{abstract}

Keywords Electric Power Plant, Solid Waste, Ash-slag Waste, Separation, Magnetic Separation, Leaching

\section{Introduction}

Unfortunately, today the most common method of industrial waste treatment in Ukraine is to place them in piles, slagheaps, tailing ponds, ash dumps and other stores. They occupy millions of hectares of fertile land and become a source of air pollution; filtrate of above stores gets into the soil and underground water.

In fuel and energy complex a significant amount of ash-slag wastes (ASW) are formed. This fact creates one of the environmental problems in regions where there are thermal power plants. Every year about 8 million tons of ash-slag wastes are produced in Ukraine, most of which are stored in ash dumps. Ash dumps near a number of stations in Ukraine are about overfilling or already overfilled, and their expansion requires significant capital expenditure, land allotment being very difficult (and in some cases impossible) $[1,2]$.

Commercial use of ash-slag materials in Ukraine in 2013 made up 5\%, while the world ASW is a commercial product used in building industry, road construction, cement industry, to strengthen mine working and for other purposes. The use of such technologies can simultaneously utilize ASW, reduce environmental impact and produce available construction materials needed for economic and infrastructure development of Ukraine regions [3].

For comparison: in Germany and Denmark ASW usage in the manufacture of building materials has reached almost $100 \%$ of their annual output, though in Germany, it is generally forbidden to have ash dumps. Up to $50-70 \%$ of the
ASW annual output is used in USA, UK, Poland, and China. Changes to the laws of India, led to an increase of ASW utilization volume from $29.6 \%$ of annual output in $2005-2007$ to $53 \%$ in $2010-2011$ in the country, this amount being about 70 million tons per year $[4,5]$.

To solve the problem of utilization of ash-slag and to cause minimal damage to the environment while creating and modernizing ASW systems, first of all, it is necessary to adhere to the following basic principles:

- $\quad$ separate removal of ash and slag;

- the possibility of $100 \%$ collection and shipment of dry ash;

- environmentally sound methods of allocation of unclaimed dry ash and slag (granulation, filling of mine workings and quarries, etc.).

- $\quad$ improving equipment and circuit design of individual units, installations and systems of ASW;

- maximum mechanization and automation of manufacturing processes.

Near the large coal-burning thermal power plants it is of current interest to involve in technology-based cycle such secondary resources as ash and slag. The main traditional direction in this area is the use of ash-slag as:

- a component in the production of Portland cement clinker;

- a substitute of sand in the production of silica brick and concrete;

- a raw material for the production of lightweight aggregates in construction.

To analyze cost-effective organizational and technical solutions the international experience of developed countries on using ash from thermal power stations has been studied.

In Ukraine ash-slag is officially called waste. Power plants offer consumers exactly the waste, but not technically finalized product with the working characteristics corresponding to building regulations.

In Western Europe and Japan ash-heaps are known to be practically eliminated at the thermal power plants. Dry ash passes to bunkers built next to the main building of the thermal power plants. For example, in Germany bunkers' capacity is $40-60$ thousand tons. Small bunkers are always 
built with the capacity to be filled during one or two days. From the bunkers the ash samples are taken for laboratory analysis. Besides, the ash is brought up to the normative requirements by technological methods of mixing and volume batching by fractional composition; then the ash is reloaded into a storage tank $[6,7]$.

The largest on the European continent firm using ash wastes from thermal power plants - «Bau Mineral» (BM) operates in Germany. It is a subsidiary company of the energy system. This company is a connecting link between thermal power plants and construction industry.

In the United States construction workers are legally obliged to apply the thermal power plants' ash in concrete and mortar. Violators are subjected to economic sanctions by the state. Thermal power plants often pay the consumer for ash extraction.

In China, ash-slags from thermal power plants are obtainable by the consumers free of charge.

Poland uses powerful economic levers, stimulating the use of ash-slag [8].

The use of ash-slag waste from heat power industry can be considered as a business direction. To achieve this, it is advisable to develop proposals of economic incentives for the use of ASW with the inclusion of the relevant provisions of the draft law "On the secondary material resources." Large-scale utilization of waste as mineral raw materials depends on the complex issues that must be solved at the state level $[8,9]$.

Thus, the purpose of the research is to study fundamentally new method of comprehensive utilization of ash-slag waste from heat power plants in the end components as well as to determine the basic parameters of the process.

\section{Materials and Methods}

Ash-slag wastes (ASW) from power plants of Dnepropetrovsk region were used as a raw material. The overall chemical composition of the waste is presented in Table 1.

Table 1. Chemical composition of ASW

\begin{tabular}{|c|c|c|c|}
\hline No. in sequence & $\begin{array}{c}\text { Component } \\
\text { Name }\end{array}$ & Content, $\%$ & $\begin{array}{c}\text { Content, } \mathrm{g} / \mathrm{kg} \\
\text { (ASW) }\end{array}$ \\
\hline 1 & $\mathrm{Al}_{2} \mathrm{O}_{3}$ & 5,37 & 53,7 \\
\hline 2 & $\mathrm{SiO}_{2}$ & 37,34 & 373,4 \\
\hline 3 & $\mathrm{CaO}$ & 2,41 & 24,1 \\
\hline 4 & $\mathrm{TiO}_{2}$ & 1,76 & 17,6 \\
\hline 5 & $\mathrm{MnO}$ & 0,57 & 5,7 \\
\hline 6 & $\mathrm{Fe}_{3} \mathrm{O}_{4}$ & 49,16 & 491,6 \\
\hline 7 & $\mathrm{CoO}$ & 0,79 & 7,9 \\
\hline 8 & $\mathrm{Rb}_{2} \mathrm{O}$ & 0,42 & 4,2 \\
\hline 9 & $\mathrm{SrO}$ & 1,30 & 13 \\
\hline 10 & $\mathrm{Y}_{2} \mathrm{O}_{3}$ & 0,13 & 1,3 \\
\hline 11 & $\mathrm{ZrO}_{2}$ & 0,55 & 5,5 \\
\hline 12 & $\mathrm{Nb}_{2} \mathrm{O}_{5}$ & 0,053 & 0,53 \\
\hline 13 & $\mathrm{SnO}$ & 0,10 & 1 \\
\hline
\end{tabular}

This material, which contains valuable components, was first sifted to a certain size and then subjected to magnetic separation to separate non-magnetic and magnetic fractions.

Method of acid leaching was used for ASW processing. The magnetic fraction was subjected to leaching by the solutions of "aqua regia", of diluted and concentrated hydrochloric acid. When selecting the process parameters of acid leaching the major point is the number of components that go into solution. It is necessary to consider all factors in leaching technology, trying to transfer the maximum number of ASW components into the solution. The study was conducted on a laboratory unit shown in Fig. 1.

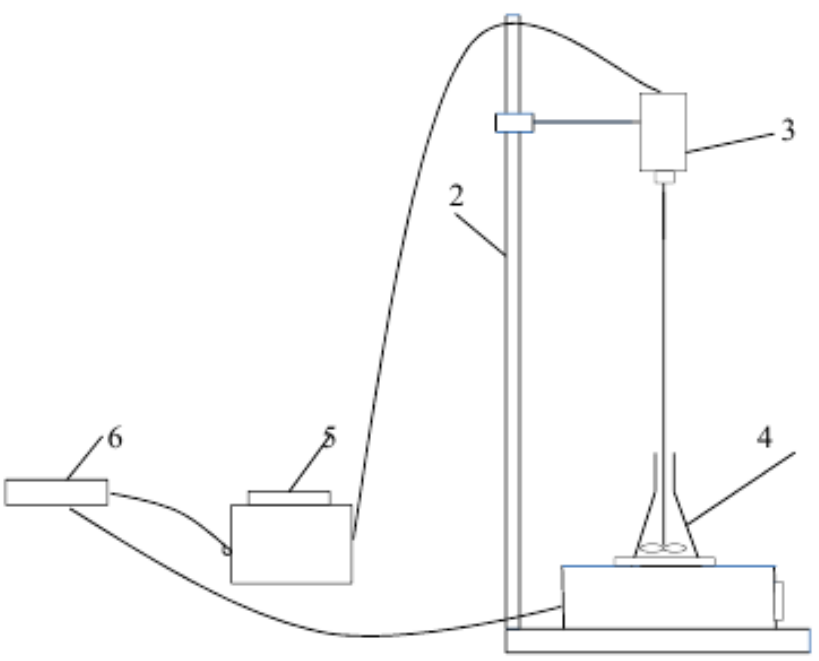

1- electric oven; 2- upright; 3-mixer; 4-heat-resistant conical flask; 5-laboratory transformer (LATR) 6-current source.

Figure 1. Laboratory unit for ASW leaching

Investigation of ASW processing on a laboratory installation was carried out as follows: a certain amount of magnetic fraction of ash-slag (MF ASW) was placed in a heat-resistant conical flask 4 which was put on an electric stove 1 . The mixer 3 was placed into conical flask which was connected to a DC current source 6 through laboratory autotransformer (LATR) 5. Leaching was carried out using as the main reagent "aqua regia", diluted and concentrated hydrochloric acid in a temperature range of $323-343^{\circ} \mathrm{K}$, for 1-4 hours at a certain voltage or revolutions of stirrer. The process having been finished, the solution was filtered, and the resulting precipitate was washed with $1 \%$ hydrochloric acid. If necessary, the precipitate was again subjected to repeated leaching in a new portion of the reagent. The solution obtained during leaching was subjected to sequential extraction and analysis of iron, titanium, aluminum and calcium oxides.

Analysis of the samples was performed using X-ray diffractometer "DRON-2.0", spectrometer "Elvax" and scanning electron microscope of "Jeol" company. Besides, samples were analyzed for the content of iron oxide by dichromate method [10, 11], for that of titanium and aluminum oxide by using "sesqui oxides" method $[10,11]$, and calcium oxide - by trilonometric method $[10,11]$. 


\section{Results and Discussion}

The micrographs of feedstock and ASW are shown in Figure 2.
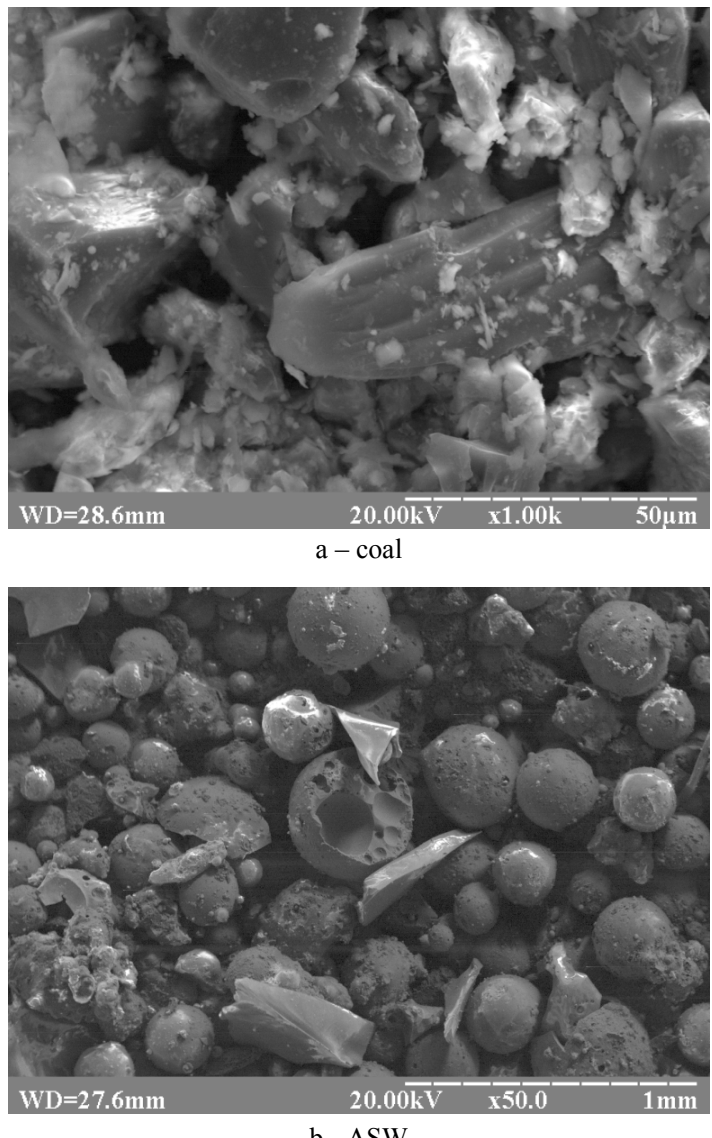

b - ASW

Figure 2. Micrographs of the starting material (a - coal dust) and waste generated (b-ASW)

Spherical shape of ASW indicates that during the combustion of coal the melt is formed, which, when falling into the water, results in the formation of spherical granules. Glowing granules on the micrographs are indicative of the presence of a magnetic fraction (oxides of iron, aluminum, titanium, chromium, manganese, etc.).

The magnetic fraction contains metal oxides, most falls on iron oxide and a small amount of silica in combination. In percentage terms, share of magnetic fraction is on average about $30-40 \%$, the rest is non-magnetic part. In further studies magnetic fraction was used. Non-magnetic part of ASW was further investigated for use as a glaze coating on the building materials of different functions [12].

It should be noted that the content of iron in magnetic concentrate varies within $95-98 \%$, which is significantly higher than that of crude ore.

By using magnetic separation thousands of tons of iron concentrate can be extracted from ash-slag waste for the steel industry. Cost of magnetic concentrate isolated from ASW of power plants running on coal by magnetic separation, is much lower than ore concentrate produced from raw ore. Thus, there is no need for complex and energy-intensive crushing and grinding equipment [13].
The main element in the initial leaching was iron, due to its high content in the waste, as well as the main impurity for the qualitative and quantitative determination of subsequent elements. The presence of iron in the samples does not allow further removal of other components of the waste.

To select the optimal reagent for further study of acid leaching, we have used the following acids (or their mixtures) as reagents: "aqua regia", diluted and concentrated hydrochloric acid, the ratio of solid and liquid S: L - 1: 7.5 for one hour at the temperature $323-343^{\circ} \mathrm{K}$. The research results are presented in Table 2 .

Table 2. The concentration of iron oxide (II) in solutions

\begin{tabular}{|c|c|c|c|}
\hline $\begin{array}{c}\text { No. in } \\
\text { sequence }\end{array}$ & $\begin{array}{c}\text { Reagent for } \\
\text { leaching }\end{array}$ & $\begin{array}{c}\text { Concentration } \\
\text { of iron (II), C } \\
(\mathrm{FeO}), \mathrm{g} / \mathrm{l}\end{array}$ & $\begin{array}{c}\text { After leaching } \\
\text { sediment mass, } \mathrm{m}, \\
\mathrm{g}\end{array}$ \\
\hline 1. & $\begin{array}{c}\text { Aqua regia }(\mathrm{HNO} 3 \\
+3 \mathrm{HCl})\end{array}$ & 6,7 & 17,38 \\
\hline 2. & $\mathrm{HCl}$ diluted & 6,14 & 16,95 \\
\hline 3. & $\mathrm{HCl}$ concentrated & 7,26 & 15,96 \\
\hline
\end{tabular}

From the survey results it can be concluded that the most favorable for leaching is concentrated hydrochloric acid, the concentration of iron being $7,26 \mathrm{~g} / \mathrm{l}$.

The next stage of the study was to determine the effect of time on the process of MF ASW acid leaching within $1-4$ hours. The results of sample analysis are presented in Table 3.

Table 3. Concentration of iron oxide (II) in concentrated hydrochloric acid solutions in time

\begin{tabular}{|c|c|c|c|}
\hline $\begin{array}{c}\text { No. in } \\
\text { sequence }\end{array}$ & $\begin{array}{c}\text { Leaching } \\
\text { time, } \tau, \mathrm{h} .\end{array}$ & $\begin{array}{c}\text { Concentration of } \\
\text { iron (II), } \mathrm{C}_{(\mathrm{FeO})}, \mathrm{g} / \mathrm{l}\end{array}$ & $\begin{array}{c}\text { After leaching } \\
\text { sediment mass, } \mathrm{m}, \mathrm{g}\end{array}$ \\
\hline 1. & 1 & 7,26 & 15,96 \\
\hline 2. & 2 & 8,93 & 16,2 \\
\hline 3. & 3 & 17,6 & 15,2 \\
\hline 4. & 4 & 17,6 & 14,6 \\
\hline 5. & 4 (repeated) & 2,79 & 11,4 \\
\hline
\end{tabular}

According to data obtained for the concentration of iron in solution, we can calculate the degree of iron extraction from the waste. The iron content in MF ASW is $96 \%$. Graphical dependence would look as shown in Figure 3.

According to the obtained graphic data, we can conclude that the degree of iron extraction has a linear dependence from time to time with a correlation coefficient $\mathrm{R}=0,99406$. That is, the degree of iron extraction increases with the increase of the process duration. Since the degree of extraction has maximum value when the time of leaching is 3 and 4 hours, 3 hours' process can be considered the most optimal and energy-saving. Increase of leaching duration will only lead to high power inputs for the process, and not to increase of the yield. The next step of our research was the iron oxide extraction from the solution. Iron oxide can be extracted as "sesqui" oxides. However, along with iron oxide (II), oxides of titanium and aluminum pass into solution. This method of iron extraction is used for further separation of iron, aluminum and titanium oxides from each other; it allows further to extract from the solution oxides of other metals having higher $\mathrm{pH}$ precipitation, such as, for example, $\mathrm{Ca}$. 


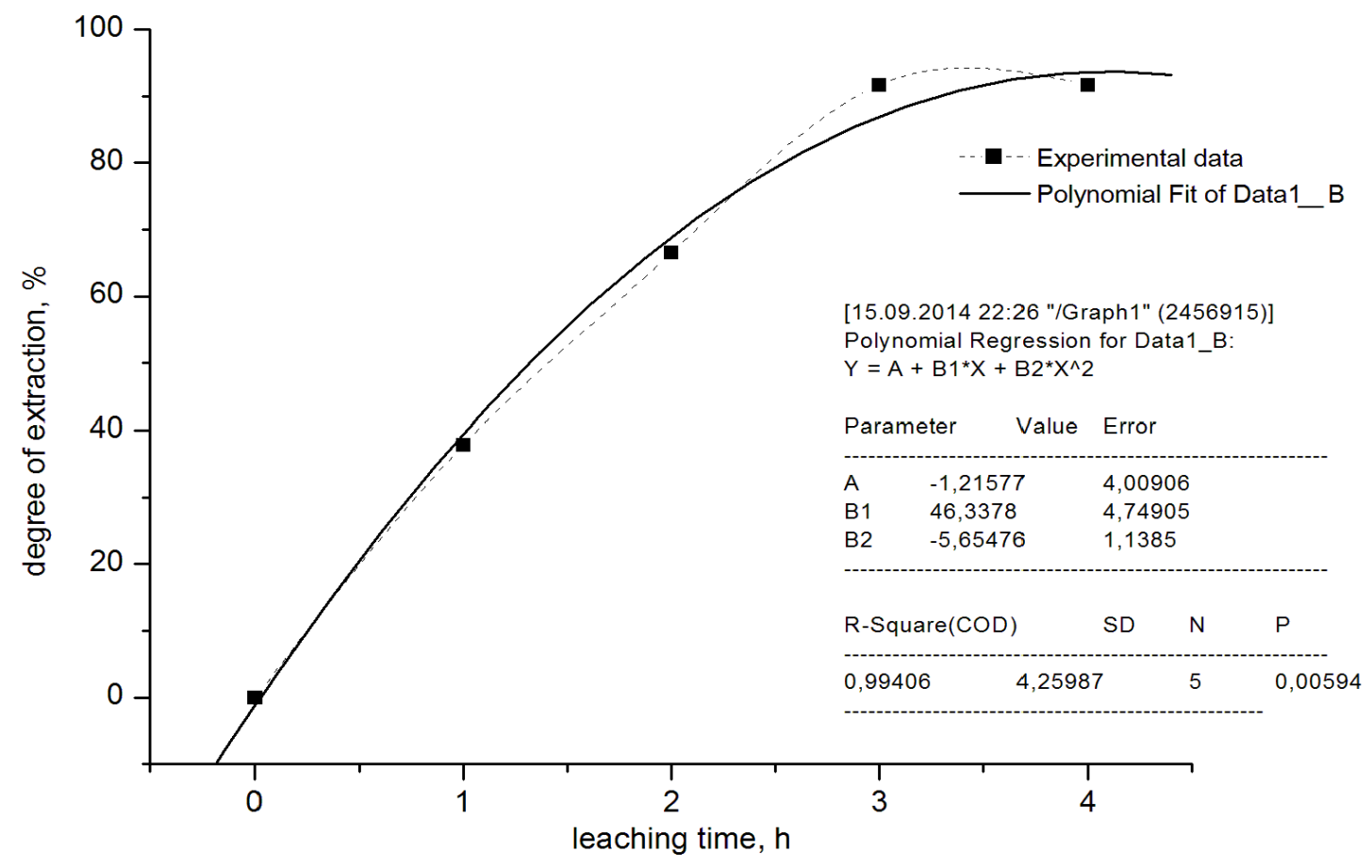

Figure 3. Dependence of the degree of iron extraction from leaching time

Extraction of "sesqui" oxides was carried out from the solutions with processing time from 1 to 4 hours to confirm our previous data on the optimum leaching time and the degree of extraction. The experimental data are presented in Table 4.

Table 4. Experimental data on "sesqui" oxides extraction from concentrated hydrochloric acid solutions in the time interval

\begin{tabular}{|c|c|c|}
\hline No. in sequence & $\begin{array}{c}\text { Leaching time, } \\
\tau, \mathrm{h}\end{array}$ & Amount, $\mathrm{mg} / \mathrm{ml}$ \\
\hline 1. & 1 & 30 \\
\hline 2. & 2 & 44 \\
\hline 3. & 3 & 74 \\
\hline
\end{tabular}

The data obtained show that the maximum number of «sesqui» oxides corresponds to leaching time of 3 hours.

The resulting iron oxide was analyzed for the content of iron, titanium and aluminum oxides. The results of X-ray and spectral measurements are presented in Figure 4 and Table 5.

Diffraction analysis showed the presence of iron oxide in the samples.

After selecting "sesqui oxides", we have conducted research on the removal of calcium oxide in solution. Determination of calcium was performed filtrate after separation "sesqui oxides." Graphical dependence will look as shown in Figure 5.

According to the obtained graphic data, we can conclude that the concentration of calcium oxide from time to time has a nonlinear dependence with the correlation coefficient

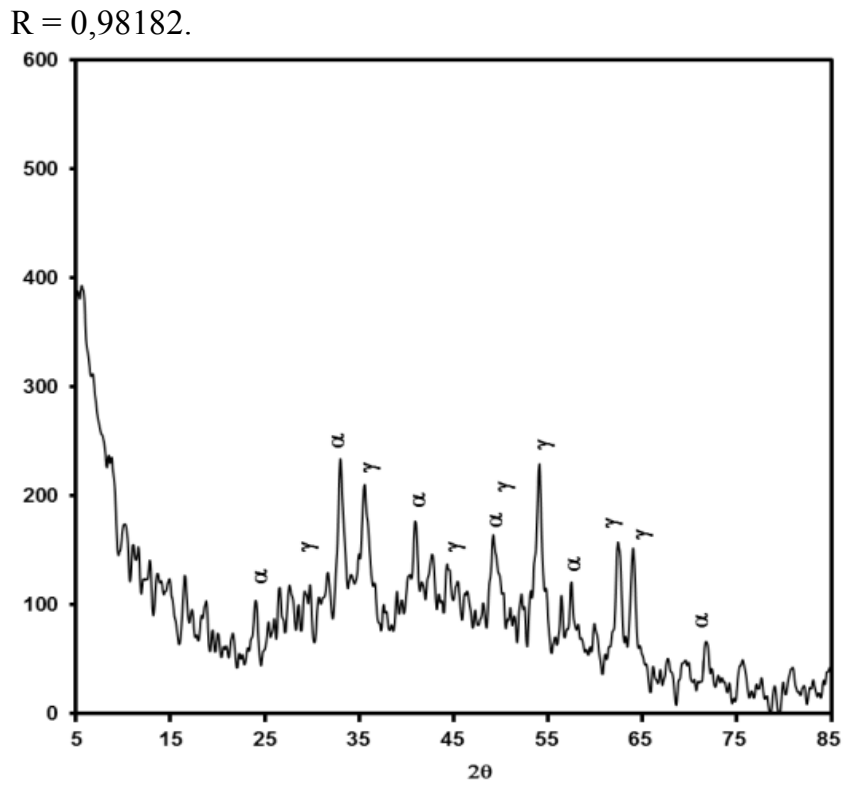

Figure 4. X-ray diffraction pattern of "sesqui" oxides: $\alpha-\alpha-\mathrm{Fe}_{2} \mathrm{O}_{3}, \gamma-\gamma-$ $\mathrm{Fe}_{2} \mathrm{O}_{3}$.

Table 5. The spectra of the "sesqui" oxide sample

\begin{tabular}{|c|c|c|c|c|c|}
\hline $\begin{array}{c}\text { No. in } \\
\text { sequence }\end{array}$ & $\begin{array}{c}\text { Atomic } \\
\text { number }\end{array}$ & Element & Series & Intensity & $\begin{array}{c}\text { Concentration, } \\
\%\end{array}$ \\
\hline 1. & 26 & $\mathrm{Fe}$ & $\mathrm{K}$ & 273474 & $99,68 \%$ \\
\hline 2. & 22 & $\mathrm{Ti}$ & $\mathrm{K}$ & 267 & $0,28 \%$ \\
\hline 3. & 13 & $\mathrm{Al}$ & $\mathrm{K}$ & 52 & $0,04 \%$ \\
\hline
\end{tabular}




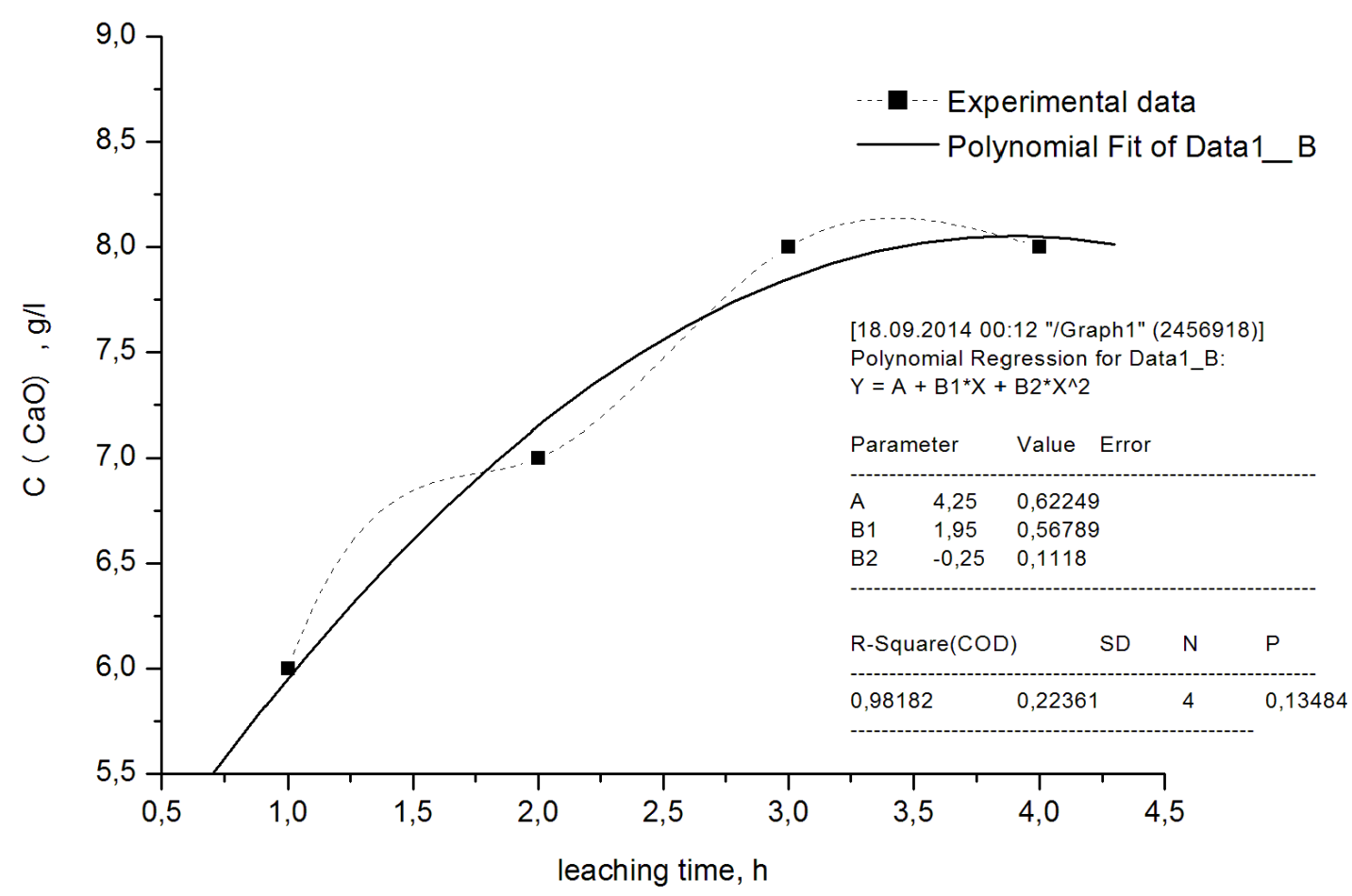

Figure 5. Dependence of calcium oxide concentration on leaching time.

\section{Conclusions}

It was established that the use of concentrated hydrochloric acid as reagent results in the maximum conversion (92\%) into the solution at temperatures $323-343^{\circ} \mathrm{K}$, during 3 hours. The process of extracting iron oxide (II) is described by the nonlinear dependence with the correlation coefficient $\mathrm{R}=0$, 99406 .

Changing the concentration of calcium oxide in the temperature interval $323-343^{\circ} \mathrm{K}$, for 3 hours is described by the nonlinear dependence with the correlation coefficient $\mathrm{R}=$ 0,98182 .

\section{REFERENCES}

[1] V. Kutovy, M. Konovalchyk, N. Kanyuk. Ash power plants as a source of environmental pollution, Bulletin of Road Traffic Institute, Vol. 1, 90-94.

[2] L. Borisenko, L. Delytsin, A. Vlasov. Prospects for the use of ash from coal-fired thermal power plants, "Geoinformmark ZAO" (Close Joint-stock Company), Moscow, 2001.

[3] V. Ivanov, I. Ivanov. Physico-chemical properties of ash waste from coal burning, Surveyor Journal, Vol. 2, No.64, 55-57.

[4] L. Solovyov, V. Pronin. The problem of disposal of industrial waste. Ash waste, Fundamental research, Vol. 3, 40-42.

[5] V. Larichkin, N. Larichkina, E. Mokrousov. Complex processing of ash waste coal-fired power plants, Recycling of waste, Vol. 3, No.27, 18-21.

[6] G. Bilyavsky, M. Padun, R. Furdui. Fundamentals of General Ecology, Lybid', Kyiv, 1995.

[7] V. Radovenchyk, M. Gomelya. Solid waste: collection, processing, storage, Condor, Kyiv, 2010.

[8] A. Urchenko. Secondary material resources of the coal industry. Handbook, Moscow, 1984.

[9] B. Bobovich, V. Devyatkin. Processing of production and consumption waste, Internet Engineering, Moscow, 2000.

[10] A. Kreshkov. Fundamentals of Analytical Chemistry. Theoretical bases. Quantitative analysis, Chemistry, Moscow, 1970 .

[11] Y. Zolotov. Fundamentals of Analytical Chemistry, Higher school, Moscow, 2000.

[12] A. Hlopitskiy, N. Makarchenko. Prospects of utilizing ashes and slag waste of thermal power plants, Universum: Technical Sciences. Electronic Science Journal, Vol. 1, 1-7.

[13] A. Hlopitskiy, N. Makarchenko. Prospects of development of processing solid slag wastes from thermal power plants in finished products, Proceedings of Odessa Polytechnic University, Vol. 3, No.42. 91-93. 